\title{
Ginkgo biloba extract enhances male copulatory behavior and reduces serum prolactin levels in rats
}

\author{
Kuei-Ying Yeh ${ }^{a}$, Hsiao-Fung Pu ${ }^{b}$, Krishna Kaphle ${ }^{c}$, Shih-Fan Lin ${ }^{a}$, Leang-Shin Wu ${ }^{c}$, \\ Jen-Hsou Lin ${ }^{\text {c }}$, Yuan-Feen Tsai ${ }^{\text {a,* }}$ \\ a Department of Physiology, College of Medicine, National Taiwan University, Taipei, Taiwan, ROC \\ ${ }^{\mathrm{b}}$ Department of Physiology, School of Medicine, National Yang-Ming University, Taipei, Taiwan, ROC \\ ${ }^{c}$ Department of Animal Science and Technology, National Taiwan University, Taipei, Taiwan, ROC
}

Received 11 September 2007; accepted 1 October 2007

Available online 10 October 2007

\begin{abstract}
The aim of this study was to investigate the effects of Ginkgo biloba extract (EGb 761) on male copulatory behavior in rats. EGb 761 (1 mg/ml) induced significant production of testosterone $(\mathrm{T})$ in rat Leydig cells in vitro. Its effects on sexual behavior were then tested in Long-Evans male rats after 7, 14, 21, or 28 days of oral gavage of vehicle (distilled water) or EGb 761 at doses of 10, 50, or $100 \mathrm{mg} / \mathrm{kg}$. Administration of $50 \mathrm{mg} / \mathrm{kg}$ of EGb 761 for 28 days and of $100 \mathrm{mg} / \mathrm{kg}$ for 14 or 21 days significantly increased intromission frequency compared to controls on the same day. An increase in ejaculation frequency was seen after treatment with $50 \mathrm{mg} / \mathrm{kg}$ of EGb 761 for 14, 21, or 28 days when compared to either the control group on the same day or the same group on day 0 . A reduction in ejaculation latency was only seen after administration of $50 \mathrm{mg} / \mathrm{kg}$ of EGb 761 for 14 days compared to the vehicle-treated group. After treatment for 28 days, no significant difference was seen in mount latency, intromission latency, serum T levels, reproductive organ weight, sperm number, or levels of the metabolite of dopamine, 3,4-dihydroxyphenylacetic acid in the brain with any dose of EGb 761, but significantly reduced serum prolactin levels and increased dopamine levels in the medial preoptic area and arcuate nucleus were seen at the dose of $50 \mathrm{mg} / \mathrm{kg}$. These findings show that EGb 761 (especially at the dose of $50 \mathrm{mg} / \mathrm{kg}$ ) enhances the copulatory behavior of male rats and suggest that the dopaminergic system, which regulates prolactin secretion, may be involved in the facilitatory effect of EGb 761.
\end{abstract}

(C) 2007 Elsevier Inc. All rights reserved.

Keywords: Ginkgo; Leydig cell; Sexual behavior; Testosterone; Prolactin; Male rat

\section{Introduction}

Sexual behavior is mainly controlled by a well-organized neural circuit that connects a variety of brain areas, but the activation of this circuit is highly dependent on gonadal hormones (Hull and Dominguez, 2007). It is well documented that testosterone $(\mathrm{T})$ plays an essential role in the control of male sexual behavior. Lack of $\mathrm{T}$ after castration abolishes sexual behavior in rodents, and the declined copulatory ability can be restored by T replacement (Hull et al., 2002).

\footnotetext{
* Corresponding author. Department of Physiology, College of Medicine, National Taiwan University, No.1 Jen-Ai Road, 1st Section, Taipei, Taiwan (100), ROC. Fax: +886 223225007.

E-mail address: yftsai@ntu.edu.tw (Y.-F. Tsai).
}

Dopamine (DA) is widely believed to facilitate male sexual function. L-DOPA treatment of Parkinsonian patients often results in enhanced libido and sexual potency (Bowers et al., 1971), and apomorphine, a DA agonist, has been used to correct erectile dysfunction (Lal et al., 1984; O'Sullivan and Hughes, 1998). Administration of DA agonists also facilitates male sexual behavior in rodents (Bitran and Hull, 1987; Melis and Argiolas, 1995).

Prolactin (PRL) influences many different types of behavior in various animal species. Peripheral administration of PRL has been reported to markedly inhibit the mating behavior of male rabbits (Hartmann et al., 1966). Subsequent studies showed that hyperprolactinemia impairs male sexual behavior in rats and mice (Bailey and Herbert, 1982; Svare et al., 1979). Although hyperprolactinemia is commonly associated with $\mathrm{T}$ deficiency in men and with ovarian dysfunction in women, it suppresses 
sexual desire without causing obvious gonadal steroid deficiency (Bancroft, 2005).

EGb 761, a standardized extract of Ginkgo biloba leaves, has been reported to have beneficial effects on memory, vigilance, cognitive functions related to aging, and dementia (DeFeudis and Drieu, 2000). It has also been shown to correct antidepressantinduced sexual dysfunction (Cohen and Bartlik, 1998); however, these data were obtained by clinical interview and self-reporting assessment by the patients. The effects of G. biloba on sexual function have not yet been investigated in animal studies. The current study was performed using a rat model to determine the effects of EGb 761 on male copulatory behavior. Since T, PRL, and DA play important roles in male sexual behavior, serum levels of T and PRL and brain levels of DA and its metabolite, 3,4dihydroxyphenylacetic acid (DOPAC), were also measured.

\section{Materials and methods}

\section{Subjects}

Male Long-Evans rats ( 8 weeks old) were purchased from the Animal Center of the National Science Council, Taipei, Taiwan. The animals were kept in groups of four in a cage $(30 \times 30 \times 20 \mathrm{~cm})$ in a temperature $\left(22 \pm 1{ }^{\circ} \mathrm{C}\right)$ - and humidity $(55 \pm$ $10 \%$ )-controlled room on a 12-h light:dark cycle (lights off at 17:00 h). Food and water were available ad libitum. The experimental protocols were approved by the Animal Care and Use Committee, College of Medicine, National Taiwan University, and all experimental procedures conformed to the National Institutes of Health Guide for the Care and Use of Laboratory Animals. When the rats were 9 weeks old, an ovariectomized female Long-Evans rat (9-12 weeks old) with an estradiol capsule implant (see below) was placed in the males' home cage for 4 days (about $90 \mathrm{~h}$ ), then removed. The males were then screened for copulatory ability using stimulus females of the same strain.

\section{Stimulus females}

Female Long-Evans rats aged 8 weeks were ovariectomized and immediately implanted with a 5-mm Silastic capsule (1.98 $\mathrm{mm} \mathrm{ID} \mathrm{and} 3.18 \mathrm{~mm} \mathrm{OD}$ ) filled with 17 â-estradiol (Sigma) under 3.5\% pentobarbital $(1 \mathrm{ml} / \mathrm{kg}$ ) anesthesia. Approximately 1 week after surgery, the females were used as sexual partners for behavioral tests.

\section{Copulation screening of test males}

The copulation screening test was performed when the male rats were 10 weeks old during the dark phase of the cycle ( $2 \mathrm{~h}$ after lights off) and under a dim red light. Each male rat was placed in a circular Plexiglas testing chamber $(45 \mathrm{~cm}$ diameter) and a stimulus female was introduced $3 \mathrm{~min}$ later, then the number and latency of mounts, intromissions, and ejaculations were recorded over a period of $15 \mathrm{~min}$. Male rats were tested three times at intervals of 5-6 days. Animals which had not ejaculated twice after three testing sessions were not used in the sexual behavior study.

\section{Treatment}

EGb 761 was purchased from Dr. Willmar Schwabe Pharmaceuticals (Karlsruhe, Germany). Male rats (approximately 12 weeks old) were randomly divided into four groups, which were given 10,50 , or $100 \mathrm{mg} / \mathrm{kg} /$ day of EGb 761 or vehicle (distilled water) ( $\mathrm{n}=10$ in each group) in a volume of $0.25 \mathrm{ml} /$ $100 \mathrm{~g}$ of body weight via oral gavage for 28 days. The EGb 761 or vehicle was given between 7:00 and 9:00 $\mathrm{h}$ each day.

\section{Copulatory behavior testing}

Copulatory behavior was measured after 7, 14, 21, and 28 days of oral administration of EGb 761 or vehicle. All behavior tests were performed between 19:00 and 22:00 $\mathrm{h}$ under a dim red light. To allow acclimatization to the test environment, each male rat was placed in a circular Plexiglas testing chamber ( $45 \mathrm{~cm}$ diameter) $3 \mathrm{~min}$ before the introduction of a sexually receptive female, then the male was allowed to copulate for $30 \mathrm{~min}$. The copulatory behavior parameters recorded were mount frequency (MF, number of mounts without penile insertion during the 30-min test period), intromission frequency (IF, number of mounts with penile insertion during the 30-min test period), ejaculation frequency (EF, number of ejaculations during the 30-min test period), mount latency (ML, latency from the introduction of the female to the first mount), intromission latency (IL, latency from the introduction of the female to the first intromission), and ejaculation latency (EL, latency from the first intromission to ejaculation). If the animal was observed on a first intromission prior to its first mount, or with intromission and ejaculation only during the 30-min testing period, we took the value of its IL as its ML for the statistical analysis. Besides, the value was counted as one mount for its first intromission. In addition, if a male rat failed to ejaculate within the 30-min observational period, the EL for this animal was recorded as $30 \mathrm{~min}$.

\section{Reproductive organ weight and sperm count}

After the last behavioral test, the males were decapitated using a guillotine and the bilateral reproductive organs (seminal vesicles, epididymis, and testes) were collected and weighed. Sperm head counting was carried out as described previously (Blazak et al., 1993). After decapsulation, the testes from each rat were homogenized in $20 \mathrm{ml}$ of ice-cold $0.9 \% \mathrm{NaCl}$ solution containing $0.01 \%$ Triton X-100 in a tissue mixer. The homogenate was allowed to settle for $1 \mathrm{~min}$, then was gently mixed and placed in ice for $1 \mathrm{~min}$. The number of sperm heads in five chambers of a hemocytometer was counted and the number of spermatozoa produced per gram of testicular tissue calculated using the equation: average number of sperm heads in five chambers $\times$ hemocytometer factor $\left(10^{4}\right) \times$ dilution $(20) \times$ dilution volume $(20)$ divided by testis weight $(\mathrm{g})$.

\section{Primary culture of rat Leydig cells}

Leydig cells were isolated from the left testes of another series of 90- to 100day-old male Long-Evans rats. The rats were killed by $\mathrm{CO}_{2}$ inhalation and the testes collected sterilely and placed in a 50-ml plastic tube (Falcon) containing medium 199 (M199, Gibco). After careful decapsulation and tearing into smaller fragments using forceps, the material was placed in a $10-\mathrm{cm}$ dish containing Hanks balanced salt solution (HBSS, Gibco) and $1.2 \mathrm{IU} / \mathrm{ml}$ of type I collagenase (Sigma), 1\% bovine serum albumin (BSA, Sigma), and $20 \mathrm{mM} \mathrm{N}-2$ hydroxyethylpiperazine- $N^{\prime}$-2-ethanesulfonic acid (HEPES, Gibco) and the dish placed at $37^{\circ} \mathrm{C}$ in a $5 \% \mathrm{CO}_{2}$ incubator for $30 \mathrm{~min}$, then the dispersed tissues were diluted with M199 and the suspension filtered through a nylon mesh $(63 \mu \mathrm{m})$ into a new 50 -ml tube, which was centrifuged at $900 \times g$ for $5 \mathrm{~min}$ at $4{ }^{\circ} \mathrm{C}$. The precipitated interstitial cells were re-suspended in $5 \mathrm{ml}$ of erythrocyte lysis buffer [0.15 $\mathrm{M} \mathrm{NH}_{4} \mathrm{Cl}, 0.1 \mathrm{mM} \mathrm{Na}_{2}$ EDTA (both from Sigma), and $12 \mathrm{mM} \mathrm{NaHCO}_{3}$ ], then the sample was again centrifuged at $900 \times \mathrm{g}$ for $5 \mathrm{~min}$ at $4{ }^{\circ} \mathrm{C}$. The pellet was re-suspended in $5 \mathrm{ml}$ of M199 and the suspension loaded on top of a step gradient $(10 \%, 20 \%, 30 \%, 40 \%$, and $50 \%)$ of Percoll (Pharmacia) and centrifuged at $170 \times \mathrm{g}$ for $10 \mathrm{~min}$ at $4{ }^{\circ} \mathrm{C}$. The Leydig cells, found in the $50 \%$ layer (Gale et al., 1982), were characterized by a bright yellow halo on phase-contrast microscopy. The cells were spun down, washed twice with M199, re-suspended in M199 containing $100 \mathrm{U} / \mathrm{ml}$ of penicillin/streptomycin and $1 \%$ BSA, plated at a density of $10^{6} / \mathrm{ml}$ on $24-$ well plates (Falcon), and incubated at $37{ }^{\circ} \mathrm{C}$ in a $5 \% \mathrm{CO}_{2}$ incubator. After $2 \mathrm{~h}$, the culture medium was changed to phenol red free-M199 and the effects of incubation for $24 \mathrm{~h}$ with different doses of EGb 761 on $\mathrm{T}$ production and viability tested, as described below.

\section{Enzyme immunoassay for testosterone in culture medium or serum}

Leydig cells were incubated in the absence or presence of EGb 761 (50, 100, 250,500 , or $1000 \mu \mathrm{g} / \mathrm{ml}$ ) for $24 \mathrm{~h}$, then the culture medium was removed and stored at $-80{ }^{\circ} \mathrm{C}$ until assayed for $\mathrm{T}$ by enzyme immunoassay (EIA), and cell viability was determined using the MTT (3-(4,5-dimethylthiazol-2-yl)-2,5diphenyl tetrazolium bromide, Sigma) reduction method. The viability of the control and treated cells was greater than $90 \%$. 


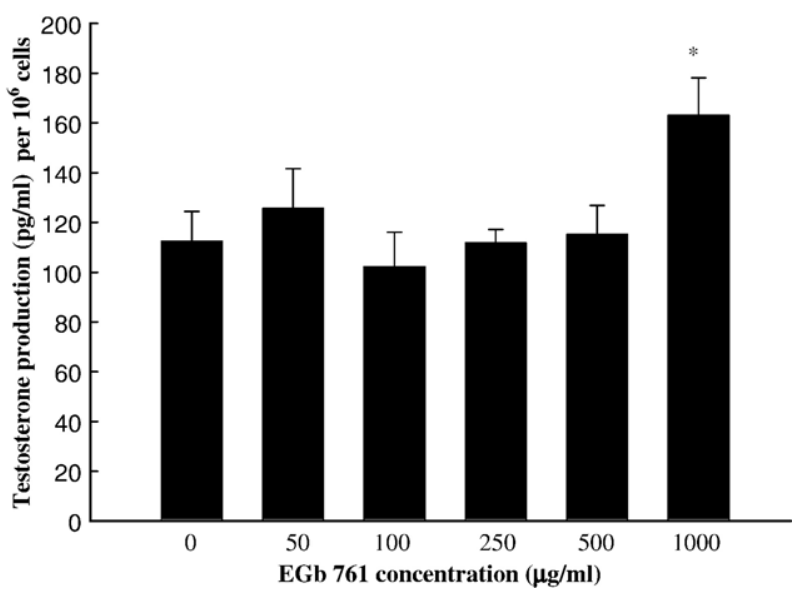

Fig. 1. Effect of EGb 761 on testosterone production by rat Leydig cells. Leydig cells were incubated with different concentrations of EGb 761 for $24 \mathrm{~h}$. The columns and bars represent the mean \pm SEM for seven independent experiments. ${ }^{*} P<0.05$ compared to vehicle-treated controls.

The culture medium from the Leydig cells was assayed for T using an EIA as described previously (Yang et al., 2004). Briefly, $50 \mu \mathrm{l}$ of diluted test medium and $50 \mu 1$ of horseradish peroxidase-coupled testosterone were added to a 96well microtiter plate (Costar 3590) coated with anti-T monoclonal antibody T-1. After incubation at room temperature for $25 \mathrm{~min}$ and two washes with phosphate-buffered saline (PBS), the color was developed using $200 \mu \mathrm{l}$ of $2.2 \mathrm{mM} o$-phenylenediamine in $0.003 \% \mathrm{H}_{2} \mathrm{O}_{2}$ at room temperature for $30 \mathrm{~min}$, then the reaction was stopped by addition of $50 \mu 1$ of $8 \mathrm{~N}$ sulfuric acid and the optical density measured at $490 \mathrm{~nm}$ and compared to a T standard curve. The assay sensitivity was $15.6 \mathrm{pg} / \mathrm{ml}$ of $\mathrm{T}$. The intra- and interassay coefficients of variation were $5-10 \%$ and $10-14 \%$, respectively.

Serum samples were assayed for $\mathrm{T}$ in an identical fashion using a $50-\mu 1$ sample of diluted serum instead of test medium.

\section{Radioimmunoassay for serum prolactin}

Male rats were sacrificed by decapitation approximately $14 \mathrm{~h}$ after the last behavioral test, and trunk blood was collected into $15 \mathrm{ml}$ test tubes, kept at room temperature for $30 \mathrm{~min}$, then centrifuged at $900 \times \mathrm{g}$ for $30 \mathrm{~min}$ at $2{ }^{\circ} \mathrm{C}$, and the serum collected and stored at $-80{ }^{\circ} \mathrm{C}$ until assayed. Serum PRL concentrations were determined by radioimmunoassay. Rat PRL (NIDDK-rPRL-I-6) was iodinated using $\mathrm{Na}^{125} \mathrm{I}$ and chloramine-T and the labeled peptide separated from free iodine on a Sephadex G-50 (superfine) column. Standard rat PRL (PRL-RP-3) and antiPRL antibodies (NIDDK-anti-rPRL-IC-5) were supplied by the NIDDK Hormone Distribution Program. The assay sensitivity was $82 \mathrm{ng} / \mathrm{ml}$ of PRL and the intra- and interassay coefficients of variation were $4.5 \%$ and $9 \%$, respectively.

\section{Measurement of dopamine and its metabolite}

Approximately $14 \mathrm{~h}$ after the last behavioral test, the brain was rapidly removed and immediately frozen in $-20{ }^{\circ} \mathrm{C}$ isopentane and then stored at

Table 1

Effect of EGb 761 on accessory sexual organ weights and sperm number

\begin{tabular}{lclllc}
\hline Group & $N$ & $\begin{array}{l}\text { Seminal } \\
\text { vesicle } \\
(\mathrm{g} / \mathrm{kg} \mathrm{BW})\end{array}$ & $\begin{array}{l}\text { Epididymis } \\
(\mathrm{g} / \mathrm{kg} \mathrm{BW})\end{array}$ & $\begin{array}{l}\text { Testes } \\
(\mathrm{g} / \mathrm{kg} \mathrm{BW})\end{array}$ & $\begin{array}{l}\text { Sperm } \\
\text { head count } \\
\left(10^{7} / \mathrm{g} \text { testes }\right)\end{array}$ \\
\hline Vehicle & 10 & $1.94 \pm 0.16$ & $3.09 \pm 0.14$ & $8.03 \pm 0.22$ & $9.29 \pm 0.54$ \\
EGb 761, 10 mg & 10 & $2.04 \pm 0.13$ & $2.98 \pm 0.12$ & $8.01 \pm 0.41$ & $10.34 \pm 0.94$ \\
EGb 761, 50 mg & 10 & $2.06 \pm 0.13$ & $3.08 \pm 0.10$ & $8.29 \pm 0.22$ & $10.31 \pm 1.05$ \\
EGb 761, 100 mg & 10 & $2.10 \pm 0.13$ & $3.12 \pm 0.09$ & $8.02 \pm 0.29$ & $10.37 \pm 0.78$ \\
\hline
\end{tabular}

The data are presented as the mean \pm SEM. No significant differences were found. $-80^{\circ} \mathrm{C}$. Serial $180-\mu \mathrm{m}$-thick coronal sections were prepared using a cryostat at $-14{ }^{\circ} \mathrm{C}$. The brain areas of the medial preoptic area (MPOA), arcuate nucleus (ARC), and median eminence (ME) were microdissected according to Palkovits (1973). Micropunched tissue samples were obtained bilaterally, homogenized at room temperature in $0.1 \mathrm{~N}$ perchloric acid, and centrifuged at $7800 \times g$ for $10 \mathrm{~min}$ at $4{ }^{\circ} \mathrm{C}$, then the supernatant was assayed for DA and DOPAC by high pressure liquid chromatography with electrochemical detection (Tsai et al., 1994). Briefly, $20 \mu 1$ of supernatant was applied to a C18 reverse phase analytical column filled with ODS-3 $(3 \mu \mathrm{m})$ (Bioanalytic System Inc., USA) using a mobile phase of $8.65 \mathrm{mM}$ heptanesulfonic acid (Sigma), $0.26 \mathrm{mM}$ EDTA (Sigma), 6.25\% acetonitrile (v/v) (Merck), 0.35\% triethylamine (v/v) (Merck), and $0.4 \%$ orthophosphoric acid (v/v) (Merck), pH 2.7-3.1, and at a flow rate of $0.5 \mathrm{ml} / \mathrm{min}$. The sensitivity of the LC-4C amperometric detector (Bioanalytic System Inc., USA) was $50 \mathrm{nA}$ full scale and the potential of the working electrode was set at $0.75 \mathrm{~V}$ with respect to an $\mathrm{Ag} / \mathrm{AgCl}$ reference electrode.

The pellets from the centrifugation were dissolved in $0.5 \mathrm{~N} \mathrm{NaOH}$ and assayed for protein by the method of Lowry et al. (1951) and the results were expressed as $\mathrm{ng} / \mathrm{mg}$ protein.

\section{Statistical analysis}

Statistic 6.0 (StatSoft Inc.) was used for statistical analyses. The data for sperm counting, weight of the reproductive organs, serum T and PRL concentrations, and DA and DOPAC levels were analyzed using one-way ANOVA. Copulatory behavioral results were evaluated by two-way mixed ANOVA with repeated measures followed by Fisher's post hoc test to establish the significance of
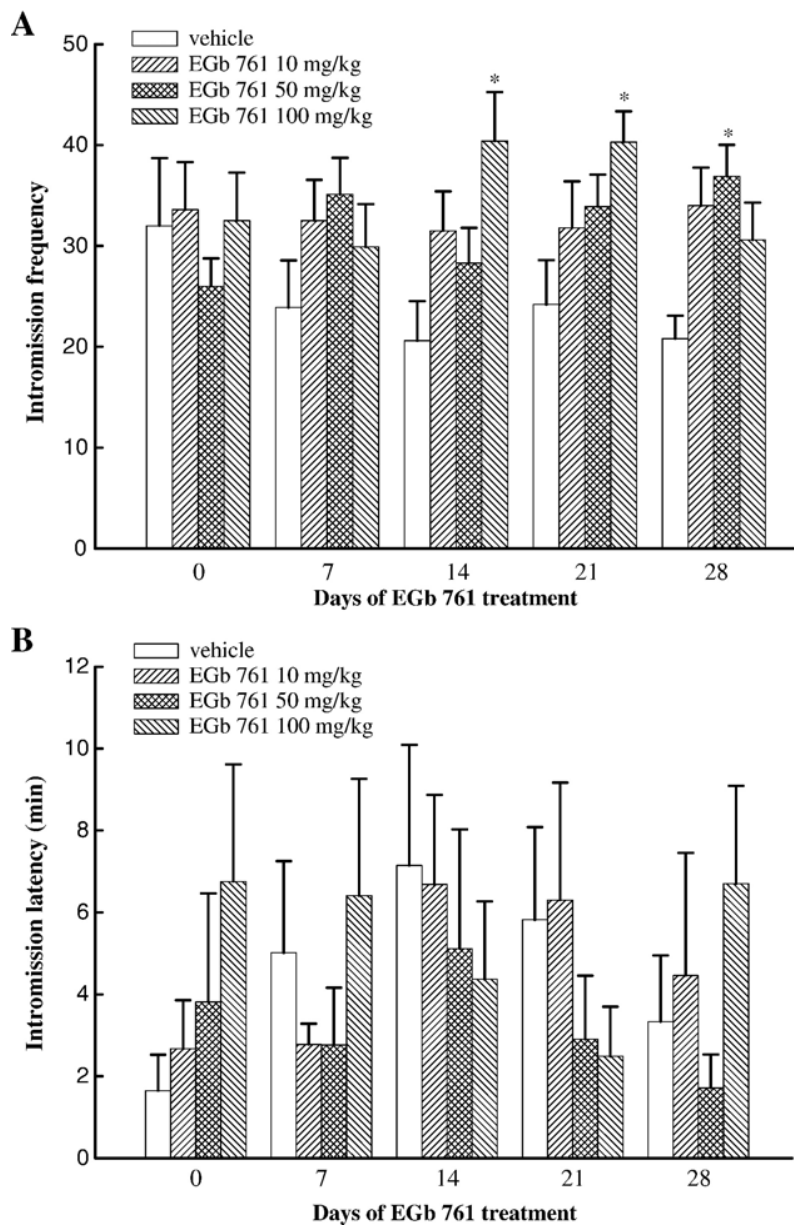

Fig. 2. Intromission frequency and latency in the different groups. (A) intromission frequency; (B) intromission latency. The data are presented as the mean $\pm \mathrm{SEM}$. ${ }^{*} P<0.05$, EGb 761 -treated group compared to the vehicle-treated group on the same day. 
A

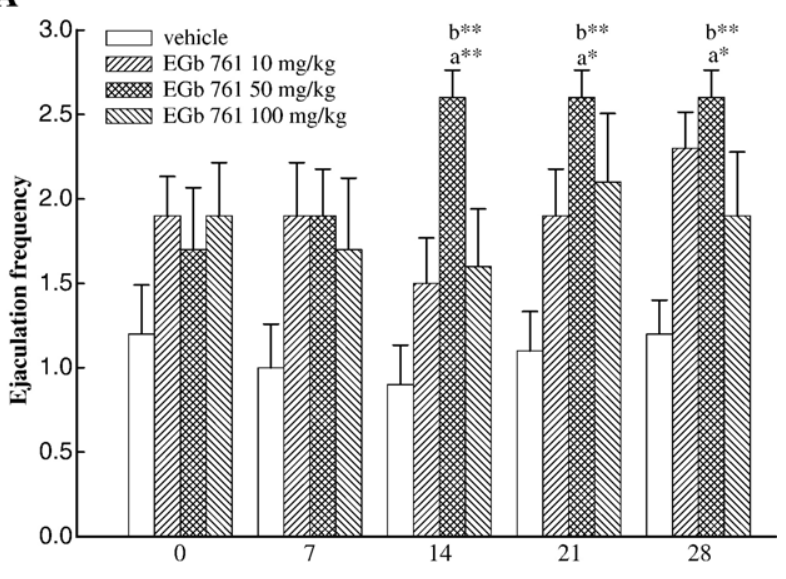

Days of EGb 761 treatment

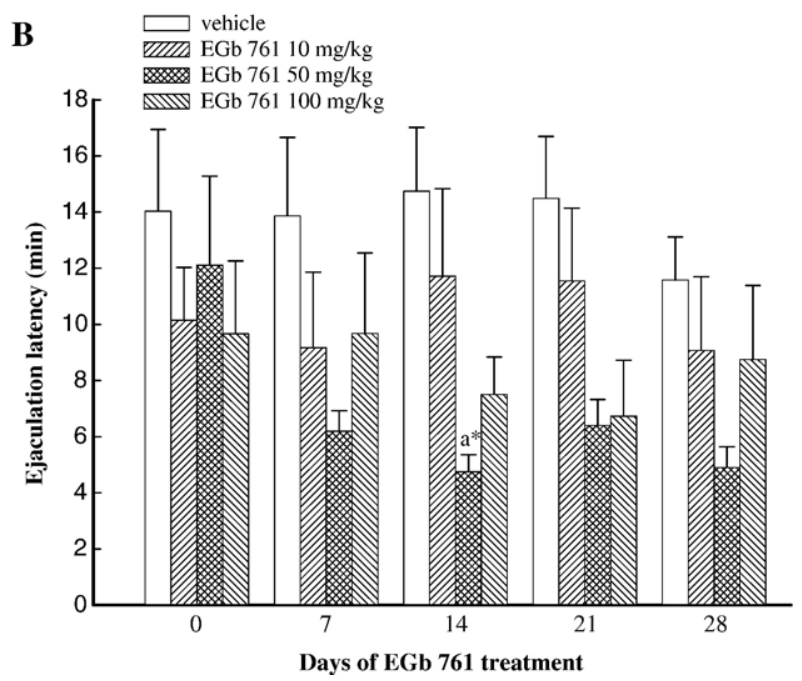

Fig. 3. Ejaculation frequency and latency in the different groups. (A) ejaculation frequency; (B) ejaculation latency. The data are presented as the mean $\pm \mathrm{SEM}$ (a, EGb 761-treated group compared to the vehicle-treated group on the same day; b, EGb 761-treated group compared to the same group on day 0 ; ${ }^{*} P<0.05$; $\left.{ }^{* *} P<0.01\right)$.

differences between means. $P$ values less than 0.05 were considered statistically significant. All quantitative data are given as the mean $\pm \mathrm{SEM}$.

\section{Results}

\section{Testosterone production by primary Leydig cells}

Cultured rat Leydig cells were treated for $24 \mathrm{~h}$ with various concentrations of EGb 761 (50, 100, 250, 500, or $1000 \mu \mathrm{g} / \mathrm{ml})$. A significant increase in $\mathrm{T}$ production compared to controls was seen at the concentration of $1000 \mu \mathrm{g} / \mathrm{ml}[F(5,36)=2.86$, $P<0.05$ ] (Fig. 1).

\section{In vivo studies}

Reproductive organ weight and sperm numbers after 28 days

The data for reproductive organ weights and sperm numbers after treatment for 28 days are shown in Table 1. No significant differences were seen. No dose of EGb 761 had any effect on
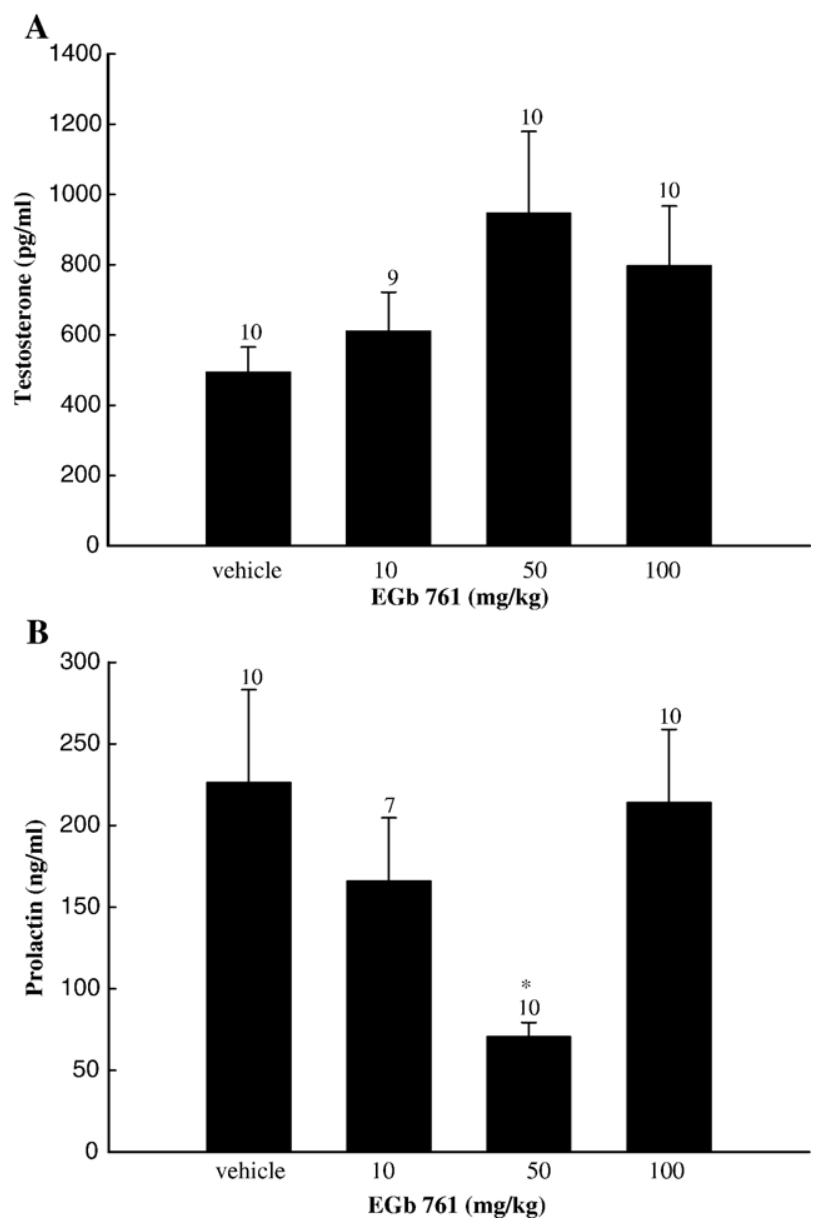

Fig. 4. Effect of 28 days of EGb 761 treatment on (A) serum T and (B) PRL levels in male rats. The data are presented as the mean \pm SEM. The numbers above the bars indicate the number of animals used per group. ${ }^{*} P<0.05$ compared to the vehicle-treated controls.

the weight of the seminal vesicle $[F(3,36)=0.25, P=0.86]$, epididymis $[F(3,36)=0.31, P=0.82]$, or testes $[F(3,36)=0.21$, $P=0.89]$ or on sperm numbers $[F(3,36)=0.38, P=0.77]$ compared to controls at the same time point.

\section{Copulatory behavior}

No significant differences in ML and MF were seen in any of the EGb 761-treated groups at any time point when compared to

Table 2

Effect of treatment with $50 \mathrm{mg} / \mathrm{kg}$ EGb 761 for 28 days on brain DA and its metabolite levels

\begin{tabular}{lllll}
\hline Brain area & Group & $\begin{array}{l}\text { DA } \\
\text { (ng/mg protein) }\end{array}$ & $\begin{array}{l}\text { DOPAC } \\
\text { (ng/mg protein) }\end{array}$ & $\begin{array}{l}\text { DOPAC/DA } \\
\text { ratio }\end{array}$ \\
\hline MPOA & Vehicle & $2.66 \pm 0.15(9)$ & $3.23 \pm 0.27(7)$ & $1.16 \pm 0.05$ \\
& EGb 761 & $3.17 \pm 0.18(8)^{*}$ & $2.53 \pm 0.26(8)$ & $0.97 \pm 0.13$ \\
ARC & Vehicle & $2.22 \pm 0.26(8)$ & $3.41 \pm 0.32(7)$ & $1.14 \pm 0.13$ \\
& EGb 761 & $3.24 \pm 0.36(7) *$ & $3.25 \pm 0.26(7)$ & $1.32 \pm 0.19$ \\
ME & Vehicle & $5.29 \pm 0.36(9)$ & $4.14 \pm 0.55(8)$ & $0.83 \pm 0.14$ \\
& EGb 761 & $6.13 \pm 0.61(8)$ & $4.62 \pm 0.50(8)$ & $0.83 \pm 0.09$ \\
\hline
\end{tabular}

The data are presented as the mean \pm SEM. The number of animals per group is indicated in parentheses.

* $P<0.05$ compared to vehicle treatment. 
controls on the same day or the same group on day 0 (data not shown).

As shown in Fig. 2A, ANOVA detected a significant dose effect in IF $[F(3,36)=3.54, P<0.05]$. Post hoc comparison revealed that animals treated with $50 \mathrm{mg} / \mathrm{kg}$ of EGb 761 for 28 days showed an increase in IF when compared to controls at the same time point $(P<0.05)$. Treatment with $100 \mathrm{mg} / \mathrm{kg}$ on day 14 and day 21 also resulted in more intromissions than in the controls on the same day $(P<0.05)$. No significant main effect of treatment $[F(3,36)=0.53, P=0.67]$ or time $[F(4,144)=$ $0.65, P=0.63$ ] was seen in IL (Fig. 2B).

Oral administration of EGb 761 induced an increase in EF. ANOVA showed a significant dose effect $[F(3,36)=5.76, P<0.01]$ and time effect $[F(4,144)=2.54, P<0.05]$ (Fig. 3A). Post hoc comparison showed that rats treated with $50 \mathrm{mg} / \mathrm{kg}$ of EGb 761 for 14,21 , or 28 days showed a significantly increased EF when compared to controls at the same time point $(P<0.05)$. Treatment with $50 \mathrm{mg} / \mathrm{kg}$ of EGb 761 for 14, 21, or 28 days also resulted in a greater $\mathrm{EF}$ than in the same group on day $0(P<0.01)$. In EL, ANOVA detected a significant effect of treatment $[F(3,36)=5.78$, $P<0.01]$ and post hoc comparison revealed that rats treated with $50 \mathrm{mg} / \mathrm{kg}$ of EGb 761 for 14 days showed a significant decrease in EL compared to vehicle-treated controls on the same day $(P<0.05)$ (Fig. 3B).

\section{Serum hormone concentrations on day 28}

No significant difference in the serum $\mathrm{T}$ concentration was seen in any of the EGb 761-treated groups compared to controls $[F(3,35)=1.58, P=0.21]$ (Fig. 4A). In contrast, a significant reduction in serum $\mathrm{PRL}$ levels was seen in the group treated with $50 \mathrm{mg} / \mathrm{kg}$ of EGb $761[F(3,33)=3.06, P<0.05]$ (Fig. 4B).

\section{Concentrations of $D A$ and its metabolite on day 28}

As shown in Table 2, a significant increase in DA levels in the MPOA $[F(1,15)=4.92, P<0.05]$ and $\operatorname{ARC}[F(1,13)=5.52$, $P<0.05]$ was seen in rats treated with $50 \mathrm{mg} / \mathrm{kg}$ of EGb 761 compared to the control group. DOPAC levels and the DOPAC/

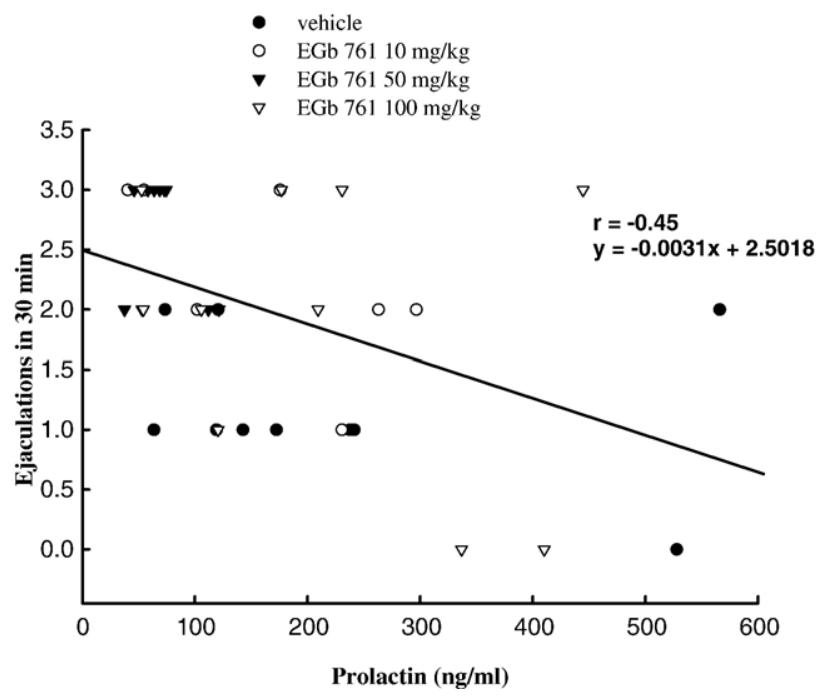

Fig. 5. Linear regression of EF and serum PRL levels in male rats treated for 28 days with various doses of EGb 761 or distilled water. $r=-0.45, P<0.01$.
DA ratio in these brain areas showed no significant differences between the control and EGb 761-treated groups. In addition, EGb 761-treated rats showed no significant change in DA and DOPAC levels in the ME compared to the control group.

Correlation analysis of EF and serum PRL levels on day 28

When the EF data for the vehicle-treated and all three EGb 761-treated groups combined were plotted against the serum PRL levels, a significant correlation was found $(r=-0.45, P<0.01)$ (Fig. 5).

\section{Discussion}

The present study demonstrated that, at the dose of $50 \mathrm{mg} / \mathrm{kg}$ body weight, EGb 761 significantly enhanced male copulatory behavior in rats, as revealed by an increase in both the IF and EF and a decrease in the EL. The results of this study support the clinical report that Ginkgo corrects male sexual dysfunction (Cohen and Bartlik, 1998). Sexual behavior is composed of two major components, sexual motivation, and copulatory performance. Sexual motivation can be measured in animals using the behavioral parameters of ML, IL, and post-ejaculatory interval, while copulatory performance is assessed by the IF, EF, and MF (Everitt, 1990). Interestingly, our results showed that Ginkgo enhanced male copulatory performance, but not sexual motivation.

In the present study, a high concentration of EGb 761 $(1000 \mu \mathrm{g} / \mathrm{ml})$ stimulated primary rat Leydig cells to produce $\mathrm{T}$ directly in vitro (Fig. 1), and long-term treatment with $50 \mathrm{mg} /$ $\mathrm{kg}$ of EGb 761 significantly enhanced male sexual behavior in rats. However, no difference in serum $\mathrm{T}$ levels was found between EGb 761-treated and control rats (Fig. 4A). A similar finding that daily oral administration of $G$. biloba for 14 days does not affect serum androgen levels in men has been reported (Markowitz et al., 2005). Our results that no changes in serum $\mathrm{T}$ levels were seen after long-term administration of EGb 761 may be explained by the androgen negative feedback mechanism. Although Ginkgo induced significant T production in Leydig cells in vitro, excessive $\mathrm{T}$ levels attenuate $\mathrm{GnRH}$ stimulation of $\mathrm{LH}$ and inhibit $\mathrm{T}$ synthesis and secretion in Leydig cells in vivo. Serum androgen levels are important in regulating sperm formation and in supporting the development of androgen-dependent organs (Grumbach and Conte, 1992). Since no significant increase in serum $\mathrm{T}$ levels after long-term EGb 761 treatment of male rats was seen in the present study, it is reasonable that EGb 761 failed to affect the reproductive organ weight or increase sperm number in male rats (Table 1). Our findings confirm a previous report that G. biloba treatment does not affect male reproductive organ weight (except the prostate gland) or sperm production in mice (Al-Yahya et al., 2006).

EGb 761 contains $24 \%$ phytoestrogens, which are composed of quercetin, kaempferol, and isorhamnetin glycosides (Gertz and Kiefer, 2004). Quercetin significantly increases cAMPinduced mRNA levels for steroidogenic acute regulatory (StAR) protein in MA-10 mouse tumor Leydig cells (Chen et al., 2007). Our result showing that EGb 761 increased T production in vitro suggests that it may increase intracellular cAMP levels and StAR 
protein expression, which is responsible for facilitating $\mathrm{T}$ synthesis in Leydig cells.

Kaempferol, another major ingredient of G. biloba, is a potent monoamine oxidase B inhibitor (MAO-B) (Sloley et al., 2000), which prevents the degradation of DA and increases its availability. The MPOA is an important brain area in the regulation of male sexual behavior, including genital reflexes, sexual motivation, and copulatory performance (Hull et al., 2002). DA in the MPOA has been demonstrated to facilitate mating and to enhance sexual responsiveness (Hull and Dominguez, 2006). Thus, the increase in DA content in the MPOA seen following long-term EGb 761 treatment (Table 2) might be mediated by the MAO-B activity of kaempferol. The increased MPOA DA levels then, in turn, would enhance copulatory behavior, as seen in the present study.

It has long been known that the ARC contains the cell bodies of tuberoinfundibular dopaminergic neurons and that the DA released from these neurons plays a critical role in inhibition of PRL secretion from the anterior pituitary (Ben-Jonathan et al., 1989). PRL release is primarily controlled by inhibitory dopaminergic signals from the ARC. In the present study, oral administration of $50 \mathrm{mg} / \mathrm{kg} /$ day of EGb 761 to male rats for 28 days resulted in a significant decrease in serum PRL levels compared to the vehicle-treated group on the same day (Fig. 4B), and significantly increased the DA content of the ARC (Table 2), indicating a correlation between a decrease in PRL levels and an increased DA concentration in the ARC.

DA turnover in the MPOA has been demonstrated to serve as a reliable indicator of sexual inactivity or sexual refractoriness (Mas et al., 1995). As shown in Table 2, we did not observe any significant change in DOPAC levels or the DOPAC/DA ratio in the MPOA, ARC, or ME after daily administration of EGb 761 for 28 days. This suggests that DA synthesis and/or metabolism might not be affected by EGb 761 in young adult male rats.

As shown in Fig. 5, there was a significant negative correlation between ejaculation frequency and serum PRL levels after long-term treatment with various doses of EGb 761, suggesting that the improvement in male sexual behavior in rats may be associated with a decrease in serum PRL levels. Our results are in agreement with the view that higher serum PRL levels impair male sexual behavior (Hull et al., 2002). Taken together, our findings suggest that EGb 761 enhances male sexual behavior in rats and decreases serum PRL levels due to increased dopaminergic activity in the central nervous system.

In conclusion, our study provides clear evidence that EGb 761 improves sexual performance in young sexually experienced male rats via a reduction in serum PRL levels. Daily oral administration of $50 \mathrm{mg} / \mathrm{kg}$ body weight of EGb 761 for 14 days was the optimal conditions for an effect on male sexual behavior. Our findings show that $G$. biloba enhances copulatory behavior, but further studies are needed to understand the mechanisms involved.

\section{Acknowledgment}

This study was supported by a grant from the National Science Council (NSC 94-2413-H002-005), ROC.

\section{References}

Al-Yahya, A.A., Al-Majed, A.A., Al-Bekairi, A.M., Al-Shabanah, O.A., Qureshi, S., 2006. Studies on the reproductive, cytological and biochemical toxicity of Ginkgo biloba in Swiss albino mice. J. Ethnopharmacol. 107, 222-228.

Bailey, D.J., Herbert, J., 1982. Impaired copulatory behaviour of male rats with hyperprolactinaemia induced by domperidone or pituitary grafts. Neuroendocrinology 35, 186-193.

Bancroft, J., 2005. The endocrinology of sexual arousal. J. Endocrinol. 186, 411-427.

Ben-Jonathan, N., Arbogast, L.A., Hyde, J.F., 1989. Neuroendocrine regulation of prolactin release. Prog. Neurobiol. 33, 399-447.

Bitran, D., Hull, E.M., 1987. Pharmacological analysis of male rat sexual behavior. Neurosci. Biobehav. Rev. 11, 365-389.

Blazak, W.F., Treinen, K.A., Juniewicz, P.E., 1993. Application of testicular sperm head counts in the assessment of male reproductive toxicity. In: Chapin, R.E., Heindel, J.J. (Eds.), Methods in Toxicology. Academic Press, San Diego, pp. 86-105.

Bowers Jr., M.B., Van Woert, M., Davis, L., 1971. Sexual behavior during L-dopa treatment for Parkinsonism. Am. J. Psychiatry 127, 1961-1963.

Chen, Y.C., Nagpal, M.L., Stocco, D.M., Lin, T., 2007. Effects of genistein, resveratrol and quercetin on steroidogenesis and proliferation of MA-10 mouse Leydig tumor cells. J. Endocrinol. 192, 527-537.

Cohen, A.J., Bartlik, B., 1998. Ginkgo biloba for antidepressant-induced sexual dysfunction. J. Sex Marital Ther. 24, 139-143.

DeFeudis, F.V., Drieu, K., 2000. Ginkgo biloba extract (EGb 761) and CNS functions: basic studies and clinical applications. Curr. Drug Targets 1, 25-58.

Everitt, B.J., 1990. Sexual motivation: a neural and behavioural analysis of the mechanisms underlying appetitive and copulatory responses of male rats. Neurosci. Biobehav. Rev. 14, 217-232.

Gale, J.S., Wakefield, J.S., Ford, H.C., 1982. Isolation of rat Leydig cells by density gradient centrifugation. J. Endocrinol. 92, 293-302.

Gertz, H.J., Kiefer, M., 2004. Review about Ginkgo biloba special extract EGb 761 (Ginkgo). Curr. Pharm. Des. 10, 262-264.

Grumbach, M.M., Conte, F.A., 1992. Disorders of sex differentiation. In: Wilson, J.D., Foster, D.W. (Eds.), Williams Textbook of Endocrinology. Saunders, Philadelphia, pp. 853-951.

Hartmann, G., Endroczi, E., Lissak, K., 1966. The effect of hypothalamic implantation of 17-beta-oestradiol and systemic administration of prolactin (LTH) on sexual behaviour in male rabbits. Acta Physiol. Acad. Sci. Hung. 30, 53-59.

Hull, E.M., Meisel, R.L., Sachs, B.D., 2002. Male sexual behavior. In: Pfaff, D.W., Arnold, A.P., Etgen, A.M., Fahrbach, S.E., Rubin, R.T. (Eds.), Hormones, Brain and Behavior, vol. 1. Academic Press, New York, pp. 3-137.

Hull, E.M., Dominguez, J.M., 2006. Getting his act together: roles of glutamate, nitric oxide, and dopamine in the medial preoptic area. Brain Res. 1126, $66-75$.

Hull, E.M., Dominguez, J.M., 2007. Sexual behavior in male rodents. Horm. Behav. 52, 45-55.

Lal, S., Ackman, D.L., Thavundayil, J.X., Kiely, M.E., Etienne, P., 1984. Effect of apomorphine, a dopamine receptor agonist, on penile tumescence in normal subjects. Prog. Neuropsychopharmacol. Biol. Psychiatry 8, 695-699.

Lowry, O.H., Rosebrough, N.J., Farr, A.L., Randall, R.J., 1951. Protein measurement with the Folin phenol reagent. J. Biol. Chem. 193, 265-275.

Mas, M., Fumero, B., Fernandez-Vera, J.R., Gonzalez-Mora, J.L., 1995 Neurochemical correlates of sexual exhaustion and recovery as assessed by in vivo microdialysis. Brain Res. 675, 13-19.

Markowitz, J.S., DeVane, C.L., Lewis, J.G., Chavin, K.D., Wang, J.S., Donovan, J.L., 2005. Effect of Ginkgo biloba extract on plasma steroid concentrations in healthy volunteers: a pilot study. Pharmacotherapy 25, 1337-1340.

Melis, M.R., Argiolas, A., 1995. Dopamine and sexual behavior. Neurosci. Biobehav. Rev. 19, 19-38.

O’Sullivan, J.D., Hughes, A.J., 1998. Apomorphine-induced penile erections in Parkinson's disease. Mov. Disord. 13, 536-539.

Palkovits, M., 1973. Isolated removal of hypothalamic or other brain nuclei of the rat. Brain Res. 59, 449-450. 
Sloley, B.D., Morlev, P., Durkin, J., Shan, J.J., Pang, P.K., Coutts, R.T., 2000. Identification of kaempferol as a monoamine oxidase inhibitor and potential neuroprotectant in extracts of Ginkgo biloba leaves. J. Pharm. Pharmacol. $52,451-459$.

Svare, B., Bartke, A., Doherty, P., Mason, I., Michael, S.D., Smith, M.S., 1979. Hyperprolactinemia suppresses copulatory behavior in male rats and mice. Biol. Reprod. 21, 529-535.
Tsai, Y.F., Tsai, H.W., Tai, M.Y., 1994. Comparison of brain dopamine depletion induced by low-dose 1-methyl-4-phenyl-1,2,3,6-tetrahydropyridine (MPTP) in young and aged rats. Neurosci. Res. 20, 27-33.

Yang, N.Y., Kaphle, K., Wang, P.H., Jong, D.S., Wu, L.S., Lin, J.H., 2004. Effects of aqueous extracts of "Betel quid" and its constituents on testosterone production by dispersed mouse interstitial cells. Am. J. Chin. Med. 32, $705-715$. 